\title{
Research on the Fusion Path of Cultural Tourism of Shenyang Red Cultural Resources
}

\author{
Feng $\mathrm{Lv}^{1}$, Jing $\mathrm{He}^{2}$, Fang $\mathrm{He}^{3}$ and Yan Xiao Wang ${ }^{4}$ \\ ${ }^{1}$ Academy of Desigh and Art, Shenyang Acrospace University, Shenyang, Liaoning, 110136, China \\ ${ }^{2}$ Academy of Desigh and Art, Shenyang Acrospace University, Shenyang, Liaoning, 110136, China \\ ${ }^{3}$ Academy of Desigh and Art, Shenyang Acrospace University, Shenyang, Liaoning, 110136, China \\ ${ }^{4}$ School of Fine Arts, Anhui Normal University, Wuhu, Anhui, 241001, China
}

\begin{abstract}
The official integration of China's cultural sector and tourism sector in 2018 has given a strong impetus to the fusion of cultural resources and tourism resources in various regions. Shenyang has rich red cultural resources and the people have deep feelings for red culture. Integrating red cultural resources with tourism resources and developing the red tourism economy will contribute to Shenyang's image of a historical and cultural city. After introducing the red cultural resources in Shenyang, the article analyzes the preliminary practice of the fusion path of red cultural tourism, and elaborates on the integration of resources, cultural creative industries, etc., providing some references for the integration development of red cultural tourism in Shenyang.
\end{abstract}

\section{The Significance of the Fusion of Red Cultural Tourism}

The development of red cultural tourism resources has important theoretical and practical significance. Red culture is an important part of our country's patriotism and national spirit, and it is also the source of cultural conviction for socialist modernization. The precious revolutionary spirit and values contained in the red culture are worthy of everyone's learning, inheritance and promotion, which will enhance the cultural confidence of the nation. Promoting and disseminating excellent red cultural resources through tourism can produce positive social effects, and also transform excellent historical and cultural resources into an economic advantage, which can not only drive the local red cultural and economic development, but also enhance the overall soft power of the city. This is exactly why the country vigorously supports the rise of red cultural resources. In 2013, the national support for red tourist attractions construction was less than 1 billion yuan. In 2020, the financial investment for red tourism construction will rise to 6 billion yuan (Figure 1). The scope of funding has also expanded from the construction of red scenic areas to red tourism projects, employee training, fine routes, etc. It can be seen that the country's emphasis and investment in red cultural tourism has continued to increase. Under the guidance of the state, the integration of red cultural tourism is constantly seeking new methods and ideas, and huge financial investment has also led to considerable economic income. China's red tourism income has gradually increased, and its share in domestic tourism income has also shown a steady upward trend. In 2010, the number of red culture tourists in China reached 430 million, generating 103.2 billion yuan in tourism revenue. In 2017, the revenue from red tourism exceeded 350 billion yuan (Figure 2) [1]. 


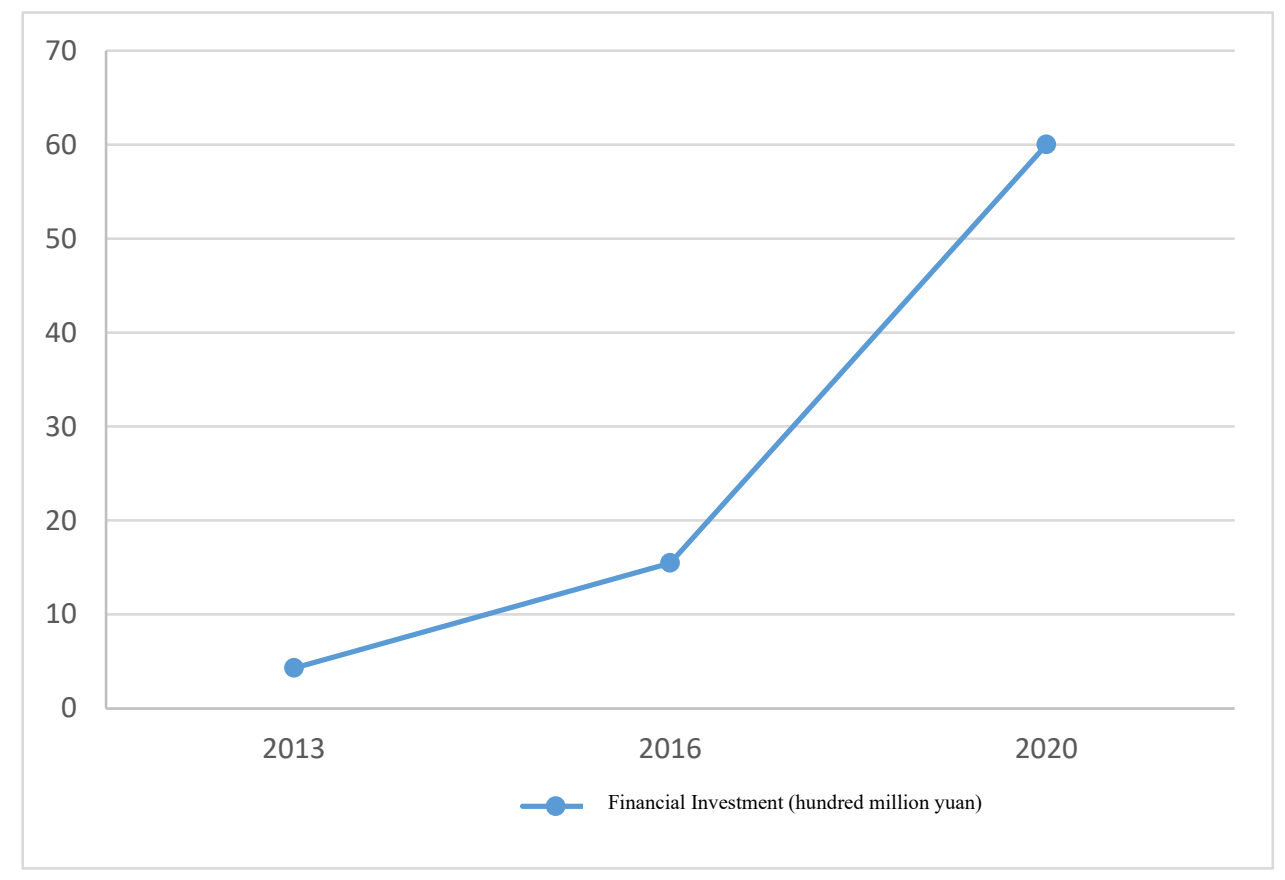

Figure 1. Statistics of Funds Supported by the Central Government for the Construction of Red Scenic Areas from 2013 to 2020

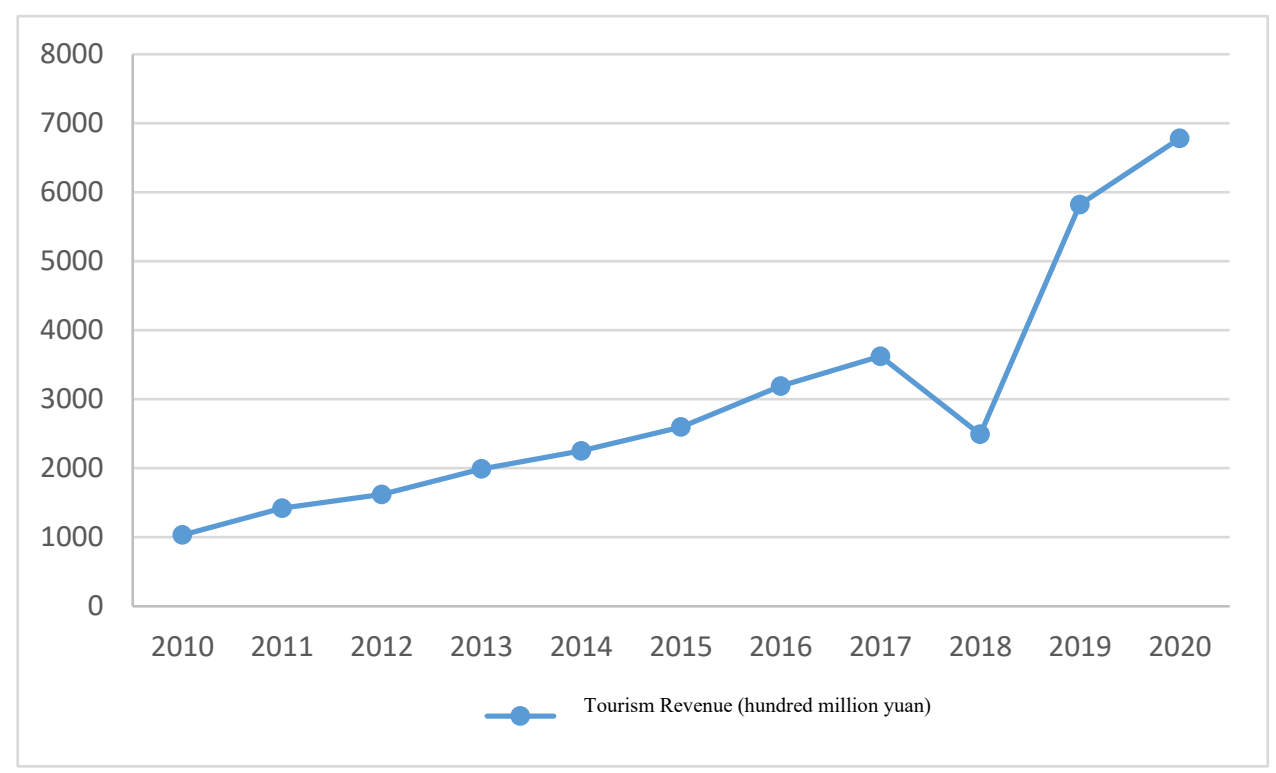

Figure 2. Proportion of Revenue of Red Tourist Attractions in Domestic

\section{Feasibility Analysis of the Integration of Shenyang Red Cultural Tourism}

\subsection{Overview of Shenyang Red Cultural Tourism Resources}

According to statistics released by Shenyang City, there are 903 tourism sites in Shenyang, of which cultural tourism resources dominate the type of tourism resources, and its red cultural resources are distributed in various districts of Shenyang, mixed with the culture and business circles in each district. It occupies an important place in Shenyang's urban cultural foundation.

Shenyang's red cultural resources cover various art forms such as sculptures, films and television dramas, stage plays, memorials, and revolutionary sites. Among them, the architectural style of the revolutionary sites covers the Manchu palaces of Qing dynasty and modern industrial styles. It has a long time span, a large number, and a wide variety[2]. Under the tide of building a red tourist city nationwide in recent years, Shenyang has also completed the census of revolutionary sites, with 88 sites of red cultural resources. The status of protection and development varies, and some have better protection and development, such as the Memorial Hall of the former site of Manchuria Provincial Committee of the Communist Party of China, the Martyrs Cemetery of the Korean War, and the "September 18th" Historical Museum. These red cultural sites have become key national protection units, which are of great significance 
both domestically and internationally. Shenyang owns these famous red cultural resources, which is also an advantage to create the integration of urban red cultural resources and tourism. However, these individual representative sites are not enough. It should also form a large tourism area in Shenyang. We should develop and expand more unknown red cultural resources that are of great significance, and let the red cultural tourism in Shenyang "flourish everywhere".

\subsection{Exploration of the Fusion of Red Cultural Tourism}

As a brilliant highlight of the fusion path of Shenyang red cultural tourism, the world-renowned "September 18th" Historical Museum has a commemorative significance in the War of Resistance Against Japan. It is a completely developed red tourism site in Shenyang, and it is also one of the important national red cultural attractions in Shenyang cultural tourism. In the 13th Five-Year Plan of Shenyang, the "September 18th" History Museum has always been the top priority in the development of red cultural resources, and it is also an excellent product in the fusion path of red cultural tourism. From September 1991 to 2008, "September 18th" History Museum went through the process of construction, expansion, secondary expansion, development, and reopening. On the day of free opening in 2008, the number of visitors received reached 40,000. It can be seen that people are enthusiastic about red culture, and they have a high degree of consciousness in actively accepting patriotic education in red culture. Therefore, Shenyang must not ignore the increasing demand for the development of local red cultural resources and the integration of red cultural tourism. "September 18th" History Museum can produce such a large social effect. In addition to the importance of its historical events, it also ascribes to a large number of authentic and detailed cultural relics, pictures, sculptures, digital image resources, and digital museum displays which truly restore the whole process of the event. Every cultural relic, every photo, and even every life-like sculpture are all so shocking, empathetic and indignant that the tourists who came to visit have accepted a profound and unforgettable red culture patriotic education. In particular, the digital museum opened online allows more visitors to overcome the constraints of time and space, and can conduct immersive online learning and visits anytime anywhere.

\section{The Necessity of Shenyang to Promote the Fusion of Cultural Tourism}

\subsection{Promoting the Characteristics of Shenyang Red Cultural Resources}

Shenyang's red culture has sprung up from the spread of Marxism by the Communist Party in the 1920s, and it has developed over a century, with a long time span and a strong atmosphere. Red tourism has local characteristics, with different red cultural facilities, art forms, and revolutionary stories. The red cultural connotation also has local characteristics. Shenyang's red cultural resources have their unique cultural characteristics of northern cities in different periods and historical backgrounds. There are many styles in the red revolutionary building ruins. For example, the former site of the Manchuria Provincial Committee of the Communist Party of China is a typical Manchu-Hanese siheyuan courtyard, with blue brick walls and a two-entrances-in courtyard structure; the former site of Fengtian Spinning Mill, now renamed Northeast Modern Textile Industry Museum, has small gourd-shaped walls, arched doors and windows, and a bell tower with ancient clocks, which presents a European architectural style; the "September 18th" History Museum has been modernized and remodeled, presenting a modern architectural style. Promoting the characteristics of red cultural connotation in Shenyang will make the city's integration of red cultural tourism more diverse.

\subsection{Promoting the Systematization of Shenyang Tourism Resources Industry}

As a part of the integration of cultural tourism in Shenyang, red cultural tourism integration is not just a fusion of cultural tourism, but also links all aspects of the cultural industry and tourism industry to ensure the smooth and efficient operation and contact of the system. Shenyang is the capital of Liaoning, and it is also the mega city with the most brilliant culture and the most abundant resources in the three provinces of Northeast China. It has rich red cultural resources, and has strong industrial support in the province and surrounding cities for tourism integration as well as a huge tourism consumer group. It can better coordinate and mobilize all walks of life to serve the integration of red cultural tourism, and the advantages of red cultural resources and tourism economy integration are obvious. Secondly, the development of the integration of red cultural tourism can not only drive the development of service industries such as entertainment, accommodation, shopping, amusement activities, transportation, catering, etc., but also promote the flow of resources and funds between industries in the city. Meanwhile, it can pave the way for other resources and tourism integration services, and accelerate Shenyang's economic development, making Shenyang grow into an international cultural tourism metropolis faster[3]. Therefore, Shenyang should keep up with the times in advancing the integration of red cultural tourism.

\section{The Methods of the Fusion Path of Shenyang Red Cultural Tourism}

\subsection{The Methods of the Fusion Path of Shenyang Red Cultural Tourism I-Building a Fusion Mechanism}

In the overall planning of Shenyang, promoting the 
integration of red cultural tourism is an important part of tourism development. With the leading of the government, we should speed up the improvement of municipal tourism unit agencies, optimize the functions of government tourism units, vigorously promote cooperation between tourism departments, units and all walks of life in society, and increase the enthusiasm of the government and society in participating in the integration of cultural tourism; we will actively seek development support funds, fully mobilize the ability of market regulation, and flexibly allocate resources. We can also develop special tourism resources in Shenyang, strengthen the protection and tourism management of red cultural resources, improve the laws and regulations on the integration of red cultural tourism in Shenyang, optimize the services of red cultural tourism in Shenyang, and create a healthy development environment; we should recruit talents to cultivate advanced, innovative and professional talent teams for the integration of red cultural tourism. Therefore, the government's cultural and tourism organizations should make overall considerations and consider the basic protection of red cultural resources, resource development, capital investment, industrial integration, talent cultivation, and public services as elements of the integration of Shenyang's red cultural tourism, combining with their own actual conditions with the characteristics of the local red culture and finding the starting point of integration of the red cultural tourism to establish a perfect service system and management mechanism for the integration of red cultural tourism in Shenyang. For the integration of red cultural tourism, Shenyang held an event of "Red Culture Journey in Shenyang" on October 26, 2018 in Liaoya Military Field Park, Baiqing Village, Sujiatun District. According to the existing red revolutionary sites, 22 fine routes of red tourism in Shenyang have been designed after long-term planning.

\subsection{The Methods of the Fusion Path of Shenyang Red Cultural Tourism II-Promoting Resource Integration}

The integration with social folk cultural resources. Shenyang has repeatedly carried out the protection and census of the red revolutionary sites, gone deep into the society and local places, strengthened the connection between red cultural resources and people's lives, fully explored local cultural elements, and combined Shenyang traditional cultural elements with red culture for re-creation[4]. Shenyang's anti-Japanese hero story, the large-scale modern drama "Huang Xiansheng", is one of the outstanding representatives. It breaks through the traditional singing-based performance style of modern drama, and for the first time combines with orchestral music to highlight the tragic and unfortunate sacrifice of the heroic character Huang Xiansheng after the "September 18th" Incident. In addition, Shenyang's red culture can be combined with its intangible cultural heritage, such as Zhong's carved porcelain, Zhang's gourd carving, Yuanping paper-cut, and An's dragon lantern. Through the inheritors' superb skills, it is displayed on a unique material carrier, and the presentation method is refreshing. It not only promotes the advancement of the traditional culture with the times, but also broadens the transmission channels of the red cultural resources and enriches the red culture tourism products of Shenyang.

The innovative integration with cultural and creative industries. Red culture has local characteristics, and the integration of Shenyang's red cultural tourism must also consider this feature. The integration of red cultural tourism is a combination of "locality" and "industrialization". Cultural tourism takes culture as a carrier and tourism as a form of communication and development. In terms of the unique characteristics of the Shenyang red culture, it must pay attention to the protection and development of cultural resources in Shenyang as well as taking into account the development law of the cultural industry, grasp the "degree" of the integrated development of the red cultural tourism, and avoid just catering to the market. We should strengthen the integration with cultural and creative industries, introduce an "innovative relationship" between Shenyang red culture and cultural and creative industries, use creativity and design to stimulate the vitality of Shenyang's local red culture, connect modern culture, combine the needs of the tourism industry, exploit the advantage of new media, and re-create and reproduce Shenyang's red cultural resources [5].

\subsection{The Methods of the Fusion Path of Shenyang Red Cultural Tourism III-Outward Expansion and Cooperation}

In the process of strengthening the integration of cultural tourism in Shenyang, social investment should be attracted and new integration paths should be explored[6]. The creative development of "cultural tourism integration plus Beijing-Shenyang cooperation" has greatly enhanced the influence of Shenyang's characteristic culture, and also promoted the integration of Shenyang's red cultural tourism, making the protection of red cultural resources more effective and the public cultural tourism services significantly improved. During the "Twelfth Five-Year Plan" period, Shenyang received 38.254 million domestic and foreign tourists, and tourism revenue reached 470.9 billion yuan, of which 3.435 million were foreign inbound tourists, and foreign exchange income reached 3.26 billion yuan. Compared with the "Eleventh Five-Year Plan," the number of tourists is 1.5 times; the total income is 2.4 times; the foreigh exchange income is 2.0 times(Figures 3 and 4)[7]. From the analysis data, we can see that the integration of cultural tourism in Shenyang has achieved temporary success, and its cultural tourism resources have gradually increased its international popularity. At the same time, it has also brought good opportunities and broad development prospect for Shenyang's red cultural tourism. 


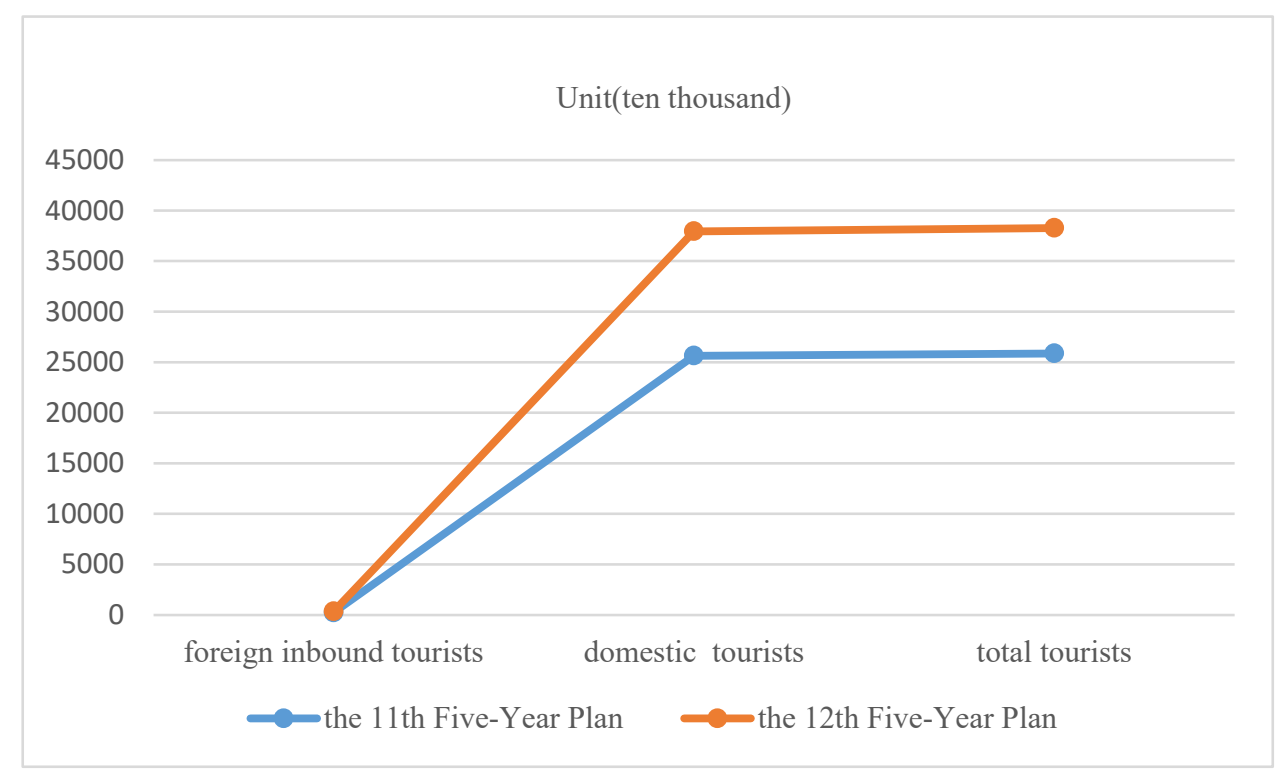

Figure 3. Comparison of the Number of Tourists Between the 11th Five-Year Plan and the 12th Five-Year Plan in Shenyang

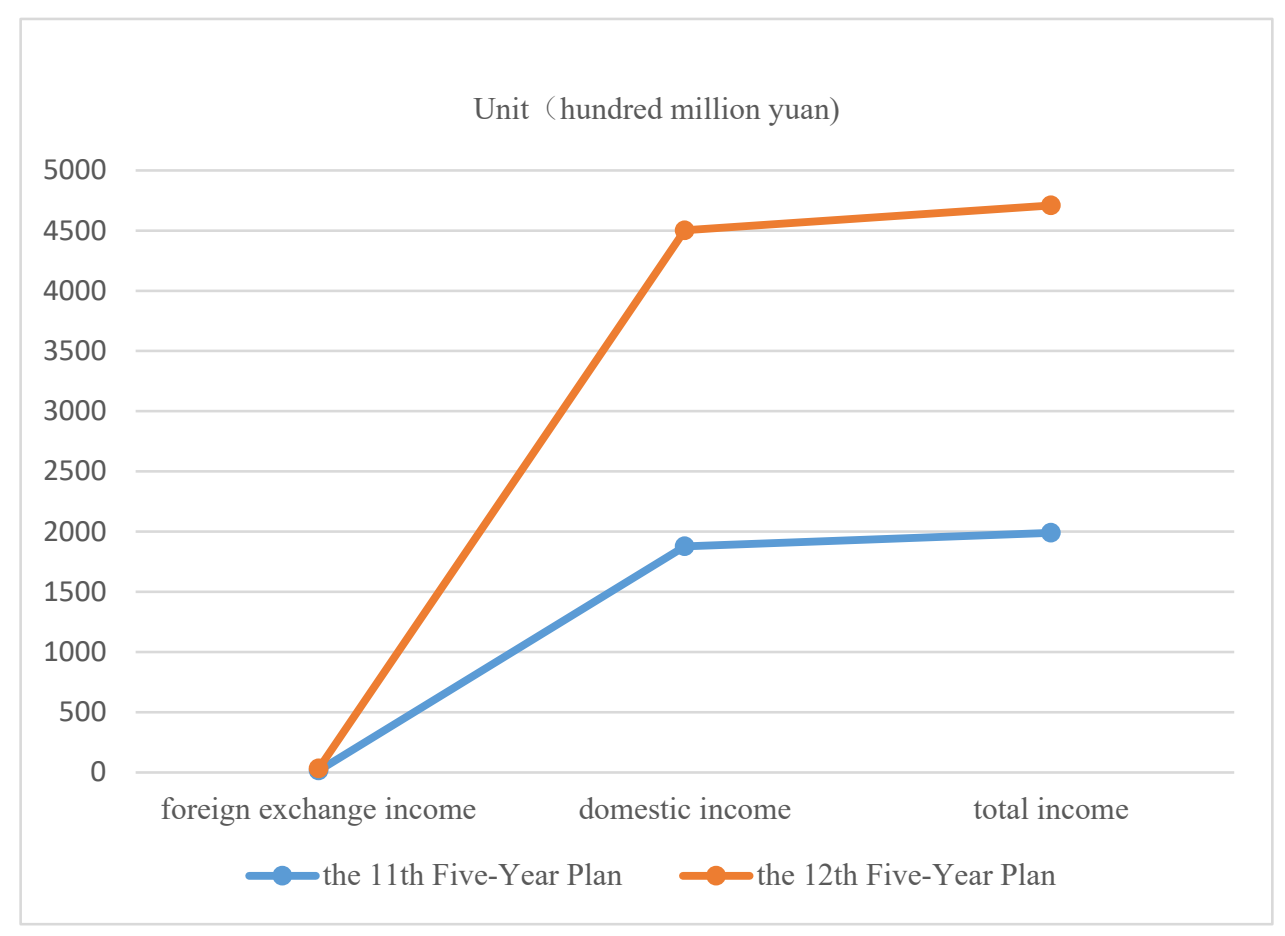

Figure 4. Comparison of Tourism Income Between the 11th Five-Year Plan and the 12th Five-Year Plan in Shenyang

\section{Thoughts on the Integration Development of Shenyang Red Cultural Tourism}

The construction and integration of the red cultural tourism project is a key project of the "Thirteenth Five-Year Plan" of Shenyang City. Based on the existing foundation, it must fully integrate the red cultural tourism resources in Shenyang in fields of intangible cultural heritage, entertainment, technology, finance, etc., strengthening the industrial research and development in multiple fields. We should accelerate the transformation of the integration of red tourism from government-led to cultural tourism enterprises and social organizations, making the red tourism resources and capital mobilization more flexible and efficient. We should actively motivate the participation of red cultural tourists in innovation, and promote the entire society of Shenyang to jointly build the cause red cultural integration.

To promote the integration of Shenyang red cultural tourism, it is also necessary to promote the integration of the cultural industry and the media. With the help of scientific and technological means and data platforms, the multi-sensory modern multimedia method is actively used to utilize VR, AR virtual reality, augmented virtual reality and other digital media to display the brilliant red culture of Shenyang. We need to establish a digital 
Shenyang as soon as possible, and build a Shenyang red cultural tourism database and information system under this background to provide integrated and efficient services for food, accommodation, purchase and travel, and provide the best tourist experience for visitors in Shenyang[8].

\section{References}

1. Tourism Industry Analysis Report of Jinggangshan City in 2020-Market Competition Status and Development Prospect Evaluation http://baogao.chinabaogao.com/lvyou/41687541687 5.html

2. Lv Feng, He Jing, He Fang. Research on the Protection and Spread of Red Cultural Resources in Shenyang [J]. Decision and Information, 2019 (07): 49-54.

3. Du Lanxiao. Promoting the Internationalization of Red Tourism Through Cultural Tourism Integration [N]. China Tourism News, 2019-02-18 (003).

4. Zhang Zucheng, Fan Jiarong, Fu Shengsheng, etc. Research on the Integrated Development of Culture and Tourism Industry: A Case Study of Longyan City [J]. Journal of Minxi Vocational \& Technical College, 2013, (2): 1-4.

5. Zhao Yue.The Development Path of Cultural Resources from the Perspective of Cultural Integration [J]. The Age of Think Tanks, 2020 (04): 262-263.

6. Liu Peng. Thoughts on Tourism Development of Yimeng Red Cultural Resources From the Perspective of Cultural Tourism Integration [J]. Renwen Tianxia, 2019 (07): 15-21.

7. The Thirteenth Five-Year Plan for Tourism Development in Shenyang-Graphic-Baidu Wenku https://wenku.baidu.com/view/d63b2503237916888 4868762caaedd3383c4b5ac.html

8. Wang Zhen. Research on Digital Design of Live Performance of Shaoshan Red Cultural Tourism [J]. Decoration, 2017 (09): 136-137 